\title{
HIV-Positivity, AIDS, and The Military Psychiatry Residency Experience
}

Ronald J. Koshes, M.D.

Uniformed Services University of the Health Sciences, Bethesda, Maryland

Follow this and additional works at: https://jdc.jefferson.edu/jeffjpsychiatry

Part of the Psychiatry Commons

Let us know how access to this document benefits you

\section{Recommended Citation}

Koshes, M.D., Ronald J. (1991) "HIV-Positivity, AIDS, and The Military Psychiatry Residency Experience," Jefferson Journal of Psychiatry. Vol. 9 : Iss. 2 , Article 6.

DOI: https://doi.org/10.29046/JJP.009.2.003

Available at: https://jdc.jefferson.edu/jeffjpsychiatry/vol9/iss2/6

This Article is brought to you for free and open access by the Jefferson Digital Commons. The Jefferson Digital Commons is a service of Thomas Jefferson University's Center for Teaching and Learning (CTL). The Commons is a showcase for Jefferson books and journals, peer-reviewed scholarly publications, unique historical collections from the University archives, and teaching tools. The Jefferson Digital Commons allows researchers and interested readers anywhere in the world to learn about and keep up to date with Jefferson scholarship. This article has been accepted for inclusion in Jefferson Journal of Psychiatry by an authorized administrator of the Jefferson Digital Commons. For more information, please contact: JeffersonDigitalCommons@jefferson.edu. 


\title{
HIV-Positivity, AIDS, and The Military Psychiatry Residency Experience ${ }^{\mathrm{a}, \mathrm{b}}$
}

\author{
Ronald J. Koshes, M.D. ${ }^{c, d}$
}

\begin{abstract}
Psychiatry residents in the military work with a diverse population of HIV-positive and AIDS patients who are in various stages in their illnesses, military careers, and acceptance of the disease process. In this circumstance, the military psychiatry resident must be a clinician, administrator, and patient advocate. Additionally, the military resident must uphold Department of Defense regulations which mandate that soldiers be both physically and emotionally fit to perform their duties. This paper describes the unique role of the military psychiatrist in working with $H I V$-positive and AIDS patients in the military setting.
\end{abstract}

\section{INTRODUCTION}

Human immunodeficiency virus (HIV) and acquired immunodeficiency syndrome (AIDS) are medical priorities for the Department of Defense. Since widespread testing was begun in 1985, over four million soldiers have been screened for the virus, and over 6000 soldiers have been found to be infected. These figures include reservists, active duty, and National Guard soldiers of the four armed forces: Army, Navy, Marines, and Air Force. Considering only active duty soldiers, over 2 million have been screened and over 2200 have been identified as HIV-positive. Screening is mandated for the entire armed forces every two years $(1,2)$. The overall rate of seroconversion has slightly declined since the start of testing, possibly reflecting the decrease of infection in certain sub-populations of the civilian community $(3,4)$. Additionally, there remains another at risk military population defined by dependents of active duty soldiers and retirees and their families (5).

In 1985, the Pentagon developed a policy of HIV screening for military recruits. Citing the need to protect the military's blood supply from infectious agents, especially during battle conditions, the Department of Defense currently denies entry into the Armed Service those who test positive. Soldiers on active duty who test

\footnotetext{
aNOTICE: The views of the author do not purport to reflect the position of the Department of the Army or the Department of Defense (para 4-3, AR 360-5).

${ }^{b}$ Presented as part of the Burroughs-Welcome/American Psychiatric Association Fellowship Symposium, "AIDS and the Psychiatric Resident," at the annual meeting of the American Psychiatric Association, San Francisco, May 1988.

'Address all correspondence to Dr. Koshes at 106 Seventh Street, S.E., Washington, D.C. 20003, (202) 543-0406.

${ }^{\mathrm{d} B u r r o u g h s-W e l c o m e / A m e r i c a n ~ P s y c h i a t r i c ~ A s s o c i a t i o n ~ F e l l o w, ~ 1987-1989 . ~}$
} 
positive, however, are allowed to remain on duty as long as they show no signs of having the disease and their condition is closely monitored. Anyone with a T-cell deficiency is eligible for retirement with a minimum of $50 \%$ salary and lifelong medical care in a Veterans Administration hospital or Army Hospital (6). If the retired soldier wants to be treated at a civilian hospital, he or she can use the CHAMPUS insurance allowed for retirees. They generally incur an additional 25\% cost. Whether on active duty or retired, the patient is eligible for drug studies and medical specialty consultations.

The HIV testing program is expensive for the military. The cost of widespread testing had been 43.1 million dollars in 1988 and was expected to double in the next two years. There are seven medical facilities in the Army which do medical evaluations of HIV-positive patients and treat those affected by AIDS.

In this milieu, military psychiatry residents often find themselves involved in research, treatment, and policy making. The following case histories are constructed to illustrate typical patients with whom military psychiatry residents are likely to come in contact. The clinical management of these patients is straightforward; emphasis is therefore placed on those aspects of the cases which illustrate the unique role of a military psychiatry resident.

\section{CASE HISTORIES}

In this first case history, a soldier was afraid to pursue diagnostic testing and treatment because of the possibility of stigma and retribution. The military psychiatry resident, aided by his knowledge of military policy and dynamic interpersonal therapy, helped the patient to get proper treatment.

Case 1. A forty year old high-ranking Sergeant diagnosed with HIV infection two years previously had been admitted to the hospital with his first episode of pneumonia. He refused a bronchoscopy for diagnostic purposes and, after some debate with the medical resident, refused treatment. He admitted to the psychiatry resident, who had been consulted to determine competency to refuse treatment, that he used intravenous heroin in Vietnam and during the late 1970's. The patient was concerned that he would be denied treatment because of a drug problem and separated from the service. The psychiatry resident informed the patient that the self-disclosure of a drug problem, past or present, would not affect his career or treatment status. He underwent bronchoscopy and pneumocystis pneumonia was diagnosed. Subsequent psychotherapy focused on acceptance of his past heroin use, guilt over being infected with HIV, and on avoiding alcohol and drugs as a current coping strategy.

The second case further illustrates how the doctor-patient relationship facilitated the healthy expression of anger in a homosexual soldier infected with HIV.

Case 2. A nineteen year old Private had a consistently low white blood cell count and suffered from an extended episode of bronchitis. An HIV test done in Germany, where he was stationed, was positive. At first, he denied any risk factors and was 
evacuated to an Army medical center for staging and reassignment. The nursing staff on the evaluation ward asked the psychiatry resident on duty for a suicide assessment because the patient was depressed. He stated that he felt as sad and hopeless as he did three years ago when he took an overdose following the breakup of an important relationship. The resident who interviewed the patient determined that the patient was not suicidal, but was feeling overwhelmed with the possibility of death from AIDS. The patient was also able to describe angry feelings towards the person who infected him. The resident encouraged the patient to become involved in an AIDS support group at the medical center, in order to explore issues of anger and victimization. In the support group, he was able to describe feeling isolated and scared as a homosexual in the military.

This next case shows how the military psychiatry resident facilitated the treatment of a military spouse and intervened in the assignment process for the soldier.

Case 3. A thirty-five year old Korean wife of an active duty soldier had been in the final stages of AIDS. Her risk factor was prostitution. She suffered from AIDS dementia and although her clinical course had been stable, she was transferred to the psychiatry ward for behavioral and pharmacologic management of her inappropriate behavior. She required extensive social work consultation because of her two infant children. The psychiatry resident worked to educate the ward staff about dementia, AIDS, and infectivity because of the staff's anxiety during the inpatient treatment. The resident at times felt at fault for exposing the staff to contagion and was the target of the staff's anger when the patient became unmanageable. Although she died one month after her arrival on the psychiatry ward, the resident was able to arrange for her children to be tested for HIV and to effect a reassignment of the husband closer to family support.

As an occupational physician, the military psychiatrist evaluated the ability of a soldier infected with HIV to perform his or her duties. The next case illustrates this.

Case 4. A twenty-six year old male Lieutenant in the Army Nurse Corps had been working satisfactorily with HIV infection for two and one-half years. He noted episodes of memory loss exemplified by forgetting to chart when medications were given, and errors in the narcotics inventories. Additionally, he displayed slowing of his speech and increasingly depressed mood for two months. His medical work-up was negative but cortical atrophy was demonstrated on the CT scan and his internist diagnosed HIV dementia. He was referred to the psychiatry resident by the internist who noted that the nurse's supervisor was concerned about his function in the workplace. His risk factor was promiscuous sexual behavior while stationed in Germany six years previously. In combined psychotherapy and antidepressant therapy, the patient adjusted to eventual retirement from the Army and arranged follow-up medical and psychiatric care at a Veterans Administration hospital near his 
mother's home. The nurse was relieved and less anxious after being retired from duty, which allowed him to focus more on quality-of-life issues.

Liaison with commanders about soldiers infected with HIV is common for the military psychiatry resident. This next case illustrates how the resident often has to educate military personnel about AIDS and HIV.

Case 5. A twenty-four year old male Private was admitted to the psychiatry ward with a one month history of feeling depressed and a one week history of suicidal ideation. He was a good worker and his Commanding Officer, as well as his First Sergeant, attested to this. On routine admission labs, the HIV test was positive. He admitted to having unprotected sexual contact with a homosexual who had the AIDS virus. He had no other symptoms and after learning that his Command structure would gladly accept him back at work, the patient's depression lifted and he was discharged. Prior to discharge, the resident met with the Commander to brief him on the soldier's condition. The Commander felt at ease about the soldier returning to duty.

\section{ROLE OF THE MILITARY PSYGHIATRY RESIDENT}

The role played by the military psychiatry resident in working with HIV-positive and AIDS patients is likely to be clinically similar to his or her civilian counterpart. The preceding cases, however, illustrated specific examples of interventions made by military psychiatry residents which required knowledge of a military system as well as knowledge of current military policy with regards to HIV and AIDS. Issues of trust, confidentiality, performance of duty, and the assignment process are salient features of these cases.

In other settings, the military psychiatry resident may face dilemmas in regard to taking care of these patients/soldiers. On an inpatient service, where group process issues are prominent, the resident may be identified as the cause of the patient's illness and be the focus of anger and animosity from the staff, as illustrated in Case 3. Concerns about contagion and moral outrage directed towards the patient may also ultimately cripple the ability of the inpatient unit to respond to any of the patients' individual treatment needs. Taking a leadership role, the resident often gears his or her interventions towards education and maintenance of a therapeutic environment.

In the outpatient clinic, the resident is asked to perform evaluations for cognitive deficits and to provide statements concerning the ability of the soldier to function in his or her job. This necessitates contact with Commanders and other supervisors who have direct knowledge of the soldier's functioning. Neuropsychological testing may be required to support the psychiatrist's recommendations. Additionally, the outpatient therapist may work with patients concerning problems of having a chronic and terminal disease, difficulties in relating to family and friends, and may help with the management of organic personality or mood disorders.

The on-call psychiatrist is often asked to respond to urgent behavioral evalua- 
tions throughout the hospital, sometimes transferring patients to the psychiatry ward for more comprehensive management of psychiatric and social problems. These issues often involve suicidality, compliance with medical treatments, and evaluation for competency to undergo or refuse diagnostic and therapeutic procedures.

The resident assigned to the HIV evaluation ward ${ }^{e}$ is asked to rapidly assess the mental status of patients who are admitted from medical facilities anywhere in the world. In some instances, acute psychiatric care is required. The resident then is involved in recommending a change of assignment, getting the patient into a support group, and arranging psychiatric follow-up at the soldier's home base.

In 1988, the American Psychiatric Association issued a policy on confidentiality and disclosure concerning AIDS patients (7). The policy states:

"If a patient refuses to agree to change his or her behavior or to notify the person(s) at risk or the physician has good reason to believe that the patient has failed to or is unable to comply with this agreement, it is ethically permissible for the physician to notify an identifiable person who the physician believes is in danger of contracting the virus."

For military psychiatrists, potential third parties may be the inhabitants of a town where the soldier is stationed, members of the soldier's unit, or family. In the military, the unit is often the soldier's entire living and working environment. In all circumstances, the soldier's Commanding Officer must be informed of HIV status because of potential problems in deploying the soldier to a war zone. In this sense, confidentiality is not maintained, and the psychiatrist must approach with caution those individuals who have a "need to know," or recommend that the soldier be reassigned to a unit or post which is more supportive of HIV/AIDS patients.

Confidentiality may be of special concern to both patients and physicians in the military. Many patients feel that if they disclose their homosexuality or drug use, that retribution will follow. Dealing with these particular situations can be difficult. Generally clinical management and adherence to military policy prevails. For instance, when a patient discloses an alcohol or drug problem, emphasis is placed on treatment and therefore appropriate referrals are made. Soldiers motivated to engage in treatment of a substance abuse or dependence problem are not administratively punished or discharged from military service. Similarly, sexual orientation may be the topic of psychotherapy sessions with active duty soldiers if the goal of the therapy shared by the patient and therapist is to bring the soldier to a better adjustment to military life. Soldiers are generally encouraged to keep issues of sexual orientation private to avoid stigma in an organization which views homosexuality as incompatible with military service.

'This ward was designed in 1986 to provide ongoing, multidisciplinary evaluation and discharge planning for HIV-positive soldiers and their families evacuated to Walter Reed Army Medical Center. Soldiers are educated about safer sex and provided with a milieu which is informative and otherwise supportive. The concept for the ward was developed through a cooperative effort of the Internal Medicine Service and the Psychiatry Service. 
Occasionally, a soldier with HIV infection displays poor social judgment or lack of control (because of HIV dementia, depression, or a personality disorder). Some of these soldiers are hospitalized until an appropriate treatment is pursued to insure compliance and good judgement. The military psychiatrist, in this case, will use appropriate somatic therapies and work extensively with the soldier's Commander to ensure proper psychosocial support at the unit and to arrange for psychiatric follow-up.

If a soldier comes from outside the continental United States with HIV, he or she is reassigned to the mainland. The psychiatrist is often involved in reassigning the soldier to a duty station which is particularly understanding of HIV-positive soldiers. The resident is often in the role of preparing patients for the stigma they will experience as HIV-infected persons both back at the unit and in their families and home communities. Isolation and an unsupportive unit is the usual scenario, one that can be devastating for the soldier whose usual experience of the Military is highspirited comradeship. Commanders will often ask questions about infectivity and some will demand that the soldier be "kicked-out" because of homosexuality or drug use, regardless of how the infection occurred. The resident often has to emphasize the primacy of the soldier's medical care in these situations.

An additional role of the military psychiatry resident falls within the realm of "industrial psychiatry." Because a soldier with HIV infection may be returned to duty, the psychiatrist is often asked to provide an opinion of the soldier's functional status. Because clinically significant HIV dementias are occurring earlier in the course of the disease than originally thought, formal cognitive evaluations are becoming routine. Those in highly skilled positions, such as air traffic controllers, are either reassigned or retired if dementia is present which interferes with function. In short, the resident must insure a soldier's fitness or recommend retirement.

Research is an important and unique aspect of military psychiatry training involving HIV/AIDS patients. Because the number of patients is so large and the Military's detection point is early, much data can be generated regarding suicidality, adjustment of patients to diagnosis, neuropsychiatric aspects of HIV disease, and incidence of psychiatric disorders in this population.

\section{CONCLUSION}

Military psychiatry residents are challenged to provide support for individuals with a serious illness which has profound psychosocial effects and consequences. All of this occurs in a large community to which both the resident and the patient have duties and responsibilities. The emergence of HIV-positivity and AIDS has been important in re-stating the significance of the "industrial" psychiatry model for military residents.

\section{REFERENCES}

1. Pentagon AIDS testing finds 5,890 infected. New York Times, 7 February 1988

2. Editor: Prevalence of human immunodeficiency virus antibody in U.S. active-duty military personnel. Journal of the American Medical Association 260(9):1205-1206, 1988 
3. Winkelstein W, Wiley JA, Padian NS, et al.: The San Francisco Men's Health Study: continued decline in HIV seroconversion rates among homosexual/bisexual men. American Journal of Public Health 78:1472-1474, 1988

4. Van Griensven GJP, De Vroome EMM, Goudsmit J, Coutinho RA: Changes in sexual behavior and the fall in incidence of HIV infection among homosexual men. British Medical Journal 298:218-221, 1989

5. Redfield RR, Markhan PP, Salahuddin SZ, Wright DC, Sarngadharan MG, Gallo RC: Heterosexually acquired HTLV-III/LAV disease; epidemiologic evidence for female-tomale transmission. Journal of the American Medical Association 254(15):2094-2096, 1985

6. Redfield RR, Wright DC, Tramont EC: The Walter Reed staging classification for HTLVIII/LAV infection. New England Journal of Medicine 314(2):131-132, 1986

7. Council on Law And Psychiatry: AIDS policy: Confidentiality and disclosure. Journal of the American Psychiatric Association 145(4):541, 1988 